\title{
THE EFFECT OF VARIOUS HOUSING COMBINATIONS ON VOLUNTARY WHEEL ACTIVITY IN MICE
}

\author{
A Thesis \\ by \\ CLAYTON LYLES CRUTHIRDS \\ Submitted to the Office of Graduate and Professional Studies of \\ Texas A\&M University \\ in partial fulfillment of the requirements for the degree of \\ MASTER OF SCIENCE
}

Chair of Committee, J. Timothy Lightfoot

Committee Members, Robin Fuchs-Young

Steven Riechman

Head of Department, Richard Kreider

May 2015

Major Subject: Kinesiology

Copyright 2015 Clayton Lyles Cruthirds 


\begin{abstract}
It is widely accepted that mice are active, social animals. Treadmill running, basal cage activity, and voluntary wheel running have all been used in order to study these qualities. Wheel running models have been used as an index of voluntary physical activity and appear to have several correlates in humans. Distances covered and voluntary aspect of many wheel running models allows researchers to study genetic motivators of activity as well as to track responses to training. Often, wheel running models employ a single mouse and wheel per cage, which precludes social interactions and may impact activity levels and other parameters due to anxiety. The_mechanisms by which this isolation modifies activity levels are of paramount importance to support accurate translation of results to human application. This study was designed to assess-the effects of housing density and wheel availability on activity levels in mice. Six outbred female SENCAR mice (National Cancer Institute, Bethesda, MD) were housed under various conditions by altering the number of animals and exercise wheels per cage. Starting at six weeks of age, mice were given wheel access in one of two cage combinations: one mouse and one wheel $(n=4)$ or two mice and one wheel $(n=$ 1). Data pertaining to distance and duration ran was recorded daily, with speed being calculated later as the third primary value of interest. Over the study span of 33 weeks the mice were randomly re-assigned to 1 mouse/ 1 wheel (total 506 days), 2 mice/1 wheel (64 days), and 2 mice/2 wheel (316 days) combinations ( $1 \mathrm{v} 1,2 \mathrm{v} 1$, and $2 \mathrm{v} 2$ respectively). While data was collected for all combinations, $1 \mathrm{v} 1$ and $2 \mathrm{v} 2$ were maintained for the longest amount of time. Overall, the SENCAR mice would be classified as high-active mice. When standardized per mouse, mice ran significantly less distance per day $(\mathrm{p}=0.0001)$ when two
\end{abstract}


mice were housed in the cage regardless of the number of wheels $(1 \mathrm{v} 1=10.01 \pm 4.02,2 \mathrm{v} 1=$ $6.19 \pm 3.35,2 \mathrm{v} 2=6.27 \pm 3.43 \mathrm{~km})$ as well as less time per day $(1 \mathrm{v} 1=309.8 \pm 109.4$, $2 \mathrm{v} 1=186.1 \pm 94.5,2 \mathrm{v} 2=157.4 \pm 65.9 \mathrm{mins} ; \mathrm{p}=0.0001)$. Conversely, speed of activity was significantly faster $(\mathrm{p}=0.0001)$ in the $2 \mathrm{v} 2$ housing situation $(1 \mathrm{v} 1=32.1 \pm 5.9,2 \mathrm{v} 1=33.38 \pm 7.0$, $2 \mathrm{v} 2=38.4 \pm 9.6 \mathrm{~m} / \mathrm{min})$. In summary, housing density and wheel availability can alter activity levels in SENCAR mice. 


\section{ACKNOWLEDGEMENTS}

I would like to thank my committee members Dr. Fuchs-Young and Dr. Riechman for serving as mentors during my time at Texas A\&M University, particularly during the formulation of my thesis.

A special thanks to Dr. Lightfoot for serving as my committee chair and academic

advisor for the past two years. Without his help and persistence this project would not have been possible.

Finally, thanks to my parents Dave and Rosemary for allowing me to pursue the schooling I have received thus far and may complete in the future. Their support has never wavered and I am forever grateful for that. 


\section{NOMENCLATURE}

PA Physical Activity

1v1 One Mouse and One Wheel per Cage

2v1 Two Mice and One Wheel per Cage

2v2 Two Mice and Two Wheels per Cage 


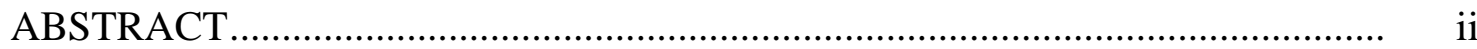

ACKNOWLEDGEMENTS ....................................................................... iv

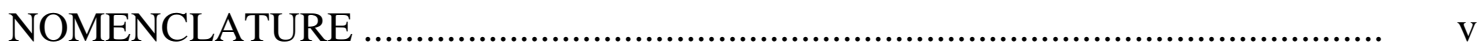

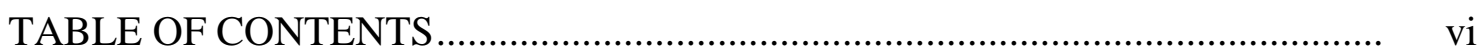

LIST OF FIGURES …....................................................................... vii

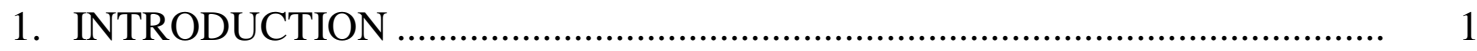

2. LITERATURE REVIEW ................................................................ 4

$2.1 \quad$ Importance of Physical Activity .................................................... 4

2.2 Why Use a Mouse Model?.............................................................. 4

2.3 Mice are Motivated to Run ................................................................ 5

2.4 Housing Density.......................................................................... 8

2.5 Wheel Size ................................................................................. 9

2.6 Wheel Surface .......................................................................... 11

2.7 Temperature .................................................................... 12

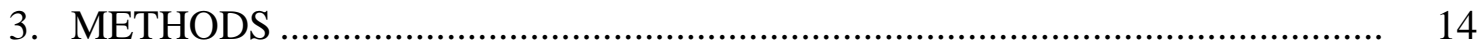

3.1 Experimental Mice...................................................................... 14

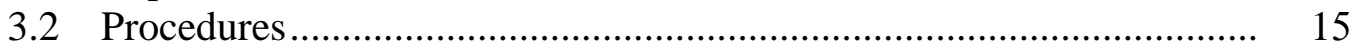

3.3 Statistics and Analysis ............................................................... 16

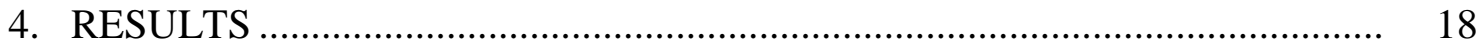

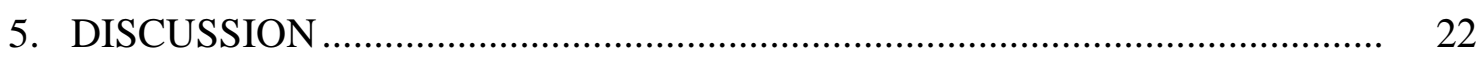

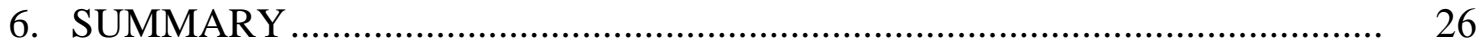

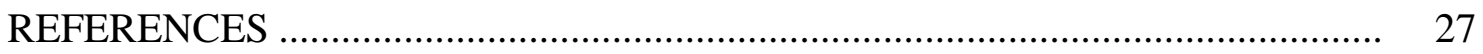

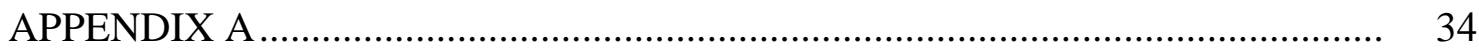




\section{LIST OF FIGURES}

FIGURE $\quad$ Page

$1 \quad$ Average Weekly Distance per Cage ................................................ 34

2 Average Daily Distance per Wheel................................................... 35

3 Average Daily Duration per Wheel ................................................ 35

$4 \quad$ Average Daily Speed per Wheel.......................................................... 35

5a Mouse S5 Daily Distance Ran ....................................................... 36

5b Mouse S6 Daily Distance Ran ......................................................... 37

6 Mice S1/S2 and S3/S4 Total Distance per Wheel .............................. 38

$7 \quad$ Mice S1/S2 and S3/S4 Total Time per Wheel .................................... 39

$8 \quad$ Mice S1/S2 and S3/S4 Average Daily Speed per Wheel......................... 40

9 Mice S1/S2 and S3/S4 Linear Fit of Distance

Difference by Day of Measure ............................................................. 41

10 Mice S1/S2 and S3/S4 Linear Fit of Duration

Difference by Day of Measure ........................................................... 42

11 Mice S1/S2 and S3/S4 Linear Fit of Speed

Difference by Day of Measure ............................................................... 43

12 Average Daily Distance per Wheel for Two Weeks.............................. 44 


\section{INTRODUCTION}

Obesity is the most common chronic illness in Western countries and has reached epidemic proportions globally $[49,53,94]$. As many as 250,000 deaths per year in the United States are attributable to a lack of regular physical activity and it is, consequently, one of the five major risk factors for obesity [60]. Physical activity has genetic as well as environmental regulatory mechanisms [10] and several different biological regulatory pathways, such as the dopaminergic system [44], are being investigated. It is anticipated that such studies will ultimately aid in developing personalized activity based strategies to prevent related diseases [44].

Using an animal model to study factors that control physical activity has many advantages, not the least of which are that the environment can be strictly controlled, the participants are relatively easy to acquire, and a variety of diets and training protocols can be applied. Many researchers have investigated the basal activity levels and exercise training potential of mice and other rodents $[1,2,6,13,27,28,50-52,63,72,82,83]$. Differences across species and strains in both activity level and training potential have been found $[6,13$, $27,28,50,51,82,83]$. Activity levels have individual variation, just as is seen in humans, but also are affected by sex, age, and strain of mouse $[10,12,75,76]$. This activity can be measured in many different ways; ranging from voluntary approaches (e.g. running wheel) to forced tests (e.g. treadmill or swimming). One of the more common approaches to measuring rodent activity is to use a voluntary wheel running model. Two primary strengths of this model, further elaborated in the subsequent sections (Review of Literature), are: 1) the environment can be controlled through the addition of enrichment devices (e.g. multiple 
running wheels, cage mates, mazes) $[26,73,89,90]$ and, 2) greater amounts of activity can be achieved with use of a running wheel compared to a treadmill [20]. Some researchers have suggested that wheel running is an unnatural or even maladaptive stimulus, but free living mice will use running wheels $[54,75]$.

Currently, it is estimated that over $75 \%$ of the genes in the human and mouse genome are orthologs that represent conserved mammalian functional genes [65]. This biological parallel aids in the eventual translation of mouse model research to humans. Likewise, physiological responses to voluntary physical activity are similar in humans and mice, which include but are not limited to, increased cardiovascular function [22] and altered muscle and mitochondrial enzyme levels $[22,46]$. For these reasons, wheel running is a good analogue for human physical activity.

Non-physiological factors can also alter rodent wheel running activity. To our knowledge, in all published studies where wheel running is employed, researchers use one animal and one wheel per cage to study physical activity, allowing access to the wheel to be tightly controlled for a given period of time, be it weeks or months $[1,5,27,45,51,88]$. Yet the removal of social cues by housing the animals individually can increase other forms of physiological remodeling, and the effect of this on activity levels is still to be determined [24, 80, 89, 90]. Additionally, while results are mixed, several studies have shown an anxiolytic effect when mice are singly housed $[61,74]$. In reality, the use of singly housed animals simplifies assessment of the exact amount of activity performed by each animal, which is critical when the activity level is the dependent variable being studied. However, because of the lack of studies designed to assess this parameter, the effects of housing density on activity levels remain almost completely unexplored. Therefore, the purpose of this study was to 
compare how housing density and wheel availability would affect physical activity levels in outbred SENCAR mice. Our hypothesis was that a 2v1 housing combination would decrease activity levels compared to the $1 \mathrm{v} 1$ combination while the addition of a second wheel in the $2 \mathrm{v} 2$ combination would lead to a recovery of this activity. 


\section{LITERATURE REVIEW}

\subsection{Importance of Physical Activity}

The United States has seen a gradual rise in prevalence of obesity over the past few decades [56, 59]. The increase in body weights, BMI, waistline measurements and other parameters of obesity, has occurred in conjunction with an inversely low level of physical activity $[4,9,48,50,55,86]$. Regular physical activity is a powerful prevention and treatment approach for hypokinetic conditions such as cardiovascular disease and type II diabetes [50]. Conditions such as these are causing healthcare costs per capita to rise yearly $[35,92]$. One study that determined the aggregated annual costs of obesity in Canada ranged from 1.27 to 11.08 billion dollars per year, representing approximately $12 \%$ of Canada's total health expenditures [85]. It has become well-established there is a genetic aspect governing physically activity, an observation across species from humans to mice and rats $[10,28,39$, 52, 64]. Due to these and other parallels, mice and other rodents represent attractive models to tease out the mechanisms regulating physical activity and energy balance.

\subsection{Why Use a Mouse Model?}

Mice are often used in biomedical research as they are a less expensive option compared to humans and allow the timely study of important physiological and biological mechanisms [1]. In addition, multiple generations can be propagated in a relatively short time, facilitating the study of transgenerational effects. Booth and colleagues and Garland and colleagues have successfully developed inbred strains of rats and mice with differing physical activity characteristics (e.g. [36, 69, 83]) while others (e.g. [28, 50, 51]) have chosen

to use previously established inbred strains to examine the biological mechanisms controlling activity. Further, years of research has led to a nearly complete map of the mouse genome 
$[17,65]$ and this fact combined with the similar physiological properties of humans and rodents have allowed researchers to make valuable connections between the two species [19, 22, 46, 81]. Cardiac and muscular capacities are of paramount importance to performance, both of which have been shown to increase from PA in humans and mice [8, 34, 40, 91]. Another benefit of rodent models is the ready access to tissues, including various regions of the brain, such as the ventral hypothalamus and dopamine system. These tissues are unavailable for research unless obtained from cadavers which offers its own biological complications. As an example, studies in rats showed that lesions in the hypothalamus decrease spontaneous locomotor activity [30]. Interestingly, the dopamine system has been linked by multiple studies to the control of PA $[11,70]$. Specifically, Knab et al. showed that administration of a D1-like agonist significantly reduced wheel running in highly active C57L/J mice, while had no effect on low active C3H/HeJ activity [44]. These results support the premise that physical activity is altered by the dopamine system and provide examples of research that would be impossible to conduct in humans. Finally, from a logistical standpoint, using mice as subjects decreases the compliance/adherence issues often encountered in studies using human subjects, especially with regard to exercise programs $[15,23,62]$.

\subsection{Mice are Motivated to Run}

One of the primary reasons that there are few issues with exercise compliance/ adherence in mice is based on an understanding of the basal activity level of mice, which supports the basis and design of this study. Many researchers have established that mice are inherently active $[6,24,27,50,51,84]$. Mouse running models were used as early as the late 
$19^{\text {th }}$ century; Stewart used one of the first wheel monitoring systems to study how alcohol, barometric pressure, and diet affected wheel running [79]. His apparatus consisted of a cylindrical shape of fine wire netting attached to whalebone pens to record revolutions on a kymograph. Technology has come a long way since then and kymographs have been replaced with electronic computers, but the process and theories are much the same.

Wheel running activity can be reported in many different fashions, most often presented as distance paired with associated duration and speed, in units ranging from kilometers per hour to meters per minute, depending on the animal of choice and length of study $[1,6,13,27,45,50]$. Yet, others summarize activity based on number of revolutions or work done [5, 21, 58, 66, 79]. Lightfoot et al. examined 41 different mice strains based on their activity levels [50] and showed that C57BR/CDJ mice ran the greatest distance $(11 \mathrm{~km})$, C58J mice ran the longest (580.6 min), and PWD/PHJ mice ran the fastest $(38.6 \mathrm{~m} / \mathrm{min})$ on a daily basis. On the lower end, $129 \mathrm{~S} 1 / \mathrm{svlmJ}$ mice ran the shortest distance and least duration, $0.4 \mathrm{~km} /$ day and $24.6 \mathrm{~min} / \mathrm{day}$, while $\mathrm{C} 3 \mathrm{H} / \mathrm{HeJ}$ ran the slowest with an average daily speed of $13.3 \mathrm{~m} / \mathrm{min}$. Also important to note is that the commonly used C57BL/6J strain is on the higher end of the activity scale in both daily distance $(7.5 \mathrm{~km})$ and average daily speed $(31.7$ $\mathrm{m} / \mathrm{min}$ ) [50]. Many of the studies described in this review utilize the C57BL/6J because of these high activity characteristics.

All three activity traits are strongly associated with gender, or have a sexual dimorphism, with females generally showing higher activity levels [50]. A previous study by the same lab reported female mice ran $20 \%$ farther on average than males [51]. Further, female $\mathrm{C} 57 \mathrm{BL} / 6 \mathrm{~J}$ mice were reported to have higher $\mathrm{Vo}_{2 \max }$ than their male counterparts when corrected for bodyweight [42]. Similarly, female Sprague-Dawley rats also ran 
significantly more than males, due to increased duration of running episodes and running speed [25]. Even when variables are employed to alter activity levels, females have been shown to be the more active sex. Jones et al. examined how food restriction altered locomotor activity in Wistar rats and showed that regardless of food group, females ran significantly farther than males [38].

A well-established mechanism of this sex based difference is the estrous cycle. As early as 1927 the periodicity of female rodent running was characterized [68]. Daily revolutions well above and below the animal average were seen in female rats within the four day estrous cycle [68]. Activity data was compared with vaginal mucosa samples to determine the association of activity and the ovulatory cycle. Using these data, it was determined that peak running days occurred just before ovulation [68]. This same trend was seen more recently in the previously mentioned Sprague-Dawley strain [2].

Even if the same sex is used in an attempt to remove this variable, others, including age, affect rodent PA [78, 82]. Mouse PA levels gradually reach a peak at around 9-12 weeks of age, much like humans [78, 82]. After this point, PA falls linearly with age until death [76]. As the animals age, other physiological aspects begin to affect PA. It has been reported that timid or fearful rats tend to be more active in wheel running studies than fearless ones [7]. It has been suggested that the act of running after a stressful encounter may be an indication that wheel running has anxiolytic effects [61]. This 'stress running' can take the place of other behavioral manifestations such as excessive grooming and teeth grinding. In humans, it has been hypothesized that running-induced stress reduction may be related to noradrenergic-galaninergic suppression, but the exact mechanism is still to be found [74]. 


\subsection{Housing Density}

Few studies have explicitly looked at the association between housing density and PA. A rare study that incorporated group housing with wheel running was conducted by Stranahan et al. [80], where male Sprague Dawley rats were used to study how wheel running altered neurogenesis in the dentate gyrus. It is important to note that even though these authors used altered housing densities and monitored wheel running, that the primary objective in this study was not to analyze the effect of group housing on activity levels.

Briefly, individual rats were given access to a running wheel while in their cage alone. In a separate arm, group housed animals (3/cage) had access to a single running wheel. After a short 12-day wheel protocol, runners housed in groups showed a significant increase in BrDU-labeled cells, a marker of DNA synthesis, in the dentate gyrus compared to group housed controls [80]. This trend was reversed in individually housed runners who showed a significant decrease in the number of labeled cells compared to individually housed controls. As reported, results from this study did not indicate that there were significant differences in amount of wheel activity in group vs. individually housed animals. However, since group values were reported only as the total cage of wheel activity divided by three, and individual values were not reported, reliable conclusions related to the effect of group housing on activity levels cannot be made.

A second significant result observed by Stranahan et al. [80] was that stress hormone corticosterone was affected by housing density and wheel access. Both individually housed cohorts (controls and runners) had higher levels of corticosterone than their group housed counterparts based on samples taken four hours into the dark cycle. The role of stress was further investigated by replacing daily BrDU injections, which had been previously proposed 
as a stressor, with a brief cold-swim test of comparable duration. Individually housed runners exposed to either daily stress (injections or cold-swim) had lower levels of cell proliferation in the dentate gyrus compared to individually housed controls [80]. Conversely, group housed runners had increased proliferation compared to their controls. Another lab had previously reported similar results, an increase in dentate gyrus proliferation after group housing running, in Sprague-Dawley rats [26]. Similar results were reported by the same lab when female C57BL/6 mice were used $[89,90]$. Results showed increases in BrDU labeled neurons in the dentate gyrus of group housed runners compared to group housed control animals [89]. Additionally, the number of BrDU labeled neurons is increased in runners compared to both controls and mice who engaged in other enrichment activities such as swimming and maze running [90]. According to the authors "these data suggest that housing density, running, and daily stress interact with each other so that the results of group housing of runners being buffered from negative effects of stress on physiological processes [90]."

\subsection{Wheel Size}

From a mechanical perspective, various labs use different wheel types depending on their animal of choice and equipment. Several materials can be used for the body of the running wheel, usually metal or plastic mesh [3, 5, 27, 28, 51, 58]. Additionally, a variety of wheel circumference sizes have been employed experimentally [3, 21]. While mechanical in nature, consistency of these factors (e.g. wheel material and size) can affect the magnitude of PA and thus, are important considerations when inter- and intra-study comparisons are being attempted.

Various studies have investigated whether wheel size, often represented in terms of circumference or diameter, alters activity levels. Collier and Leshner compared wheels with 
circumferences of $1,117 \mathrm{~mm}$ and 556mm [21]. Male C57BL/6J mice ran significantly farther on the small wheels, which investigators attributed to the significantly greater number of revolutions per day achieved with the small wheels (9000 rev) vs. the larger wheels (3500 rev). However, when the varying weights of the wheels were taken into consideration in the calculation of the total work per day, this difference was eliminated, suggesting that the wheel circumference did not matter as much as the total work per day. Banjanin and Mrosovsky used wheels which had a circumference of $550 \mathrm{~mm}$ and width of $75 \mathrm{~mm}$ for the large option and 408mm x $60 \mathrm{~mm}$ for the smaller version [3]. Choice preference was tested by placing both a small and large wheel in cages with a single mouse. To negate position preference the two wheels were interchanged halfway through the test period. Male C57BL/6 mice in these cages ran significantly more revolutions per day on the larger of the two wheels [3]. Mrosovsky's lab used these same wheels in an earlier study with golden hamsters [58] and showed that the use of the same preferential test set up showed significantly more usage of the $(550 \mathrm{~mm})$ wheel over the smaller $(408 \mathrm{~mm})$ option. It is important to note here that the large wheel used by Banjanin and Mrosovsky is similar in size to the small wheel used by Collier so an absolute comparison is difficult. Banjanin and Mrosovsky neglected to report total work done, as Collier did, in order to normalize the activity data. Using these studies as a benchmark it appears a wheel size 'sweet spot' exists near wheel circumferences of 545 and 565 millimeters.

A second factor to consider when altering wheel size is the associated change in wheel resistance. The two main factors that can affect the wheel resistance are efficiency of the axle/bearing and weight of the wheel, the later often increasing with wheel size. Konhilas et al. [45] directly studied the effect of wheel resistance on PA and several other 
physiological characteristics by designing a special adjustable wheel that allowed modification of load [45]. In this study, male C57B1/6 mice were randomized into sedentary, no resistance, low resistance, and high resistance groups. Briefly, the no resistance group was used as a standard for the entirety of the study while the other two groups received gradual increases in their wheel resistance until the resistances equaled 5 grams (low resistance) and 12 grams (high resistance). Only when the load on the wheel was increased past 9 grams in the high resistance group did the mice run significantly less distance, compared to the no resistance and low resistance groups.

After further analysis, Konhilas et al. determined that mice can tolerate up to $\sim 25 \%$ of their body weight in resistance load without affecting activity level, as measured by distance, time, and speed [45]. In the earlier study by Collier and Leshner [21], the wheel resistance was taken into consideration by measuring how many grams were required to turn the wheels $1 / 4$ turn, which was determined to be 5.01 and 6.70 grams, respectively, for the $1,117 \mathrm{~mm}$ and $556 \mathrm{~mm}$ wheels. While the smaller wheels revolved significantly more times, less force is required, equalizing the work done [21]. The bodyweights of the mice used by Collier and Leshner were not listed. However, since both investigative teams used the same mouse strain, the $25 \%$ rule established by Konhilas et al. [45] appears to be applicable in both studies.

\subsection{Wheel Surface}

Once a wheel size is selected there are a variety of materials currently in use to construct the wheels. In the study previously discussed, Banjanin and Mrosovsky compared activity levels on standard rod wheels, plastic mesh wrapped wheels, and solid floor wheels [73]. The standard rod wheels had a circumference of $550 \mathrm{~mm}$ and $1.6 \mathrm{~mm}$ metal rods spaced $12 \mathrm{~mm}$ apart. The remaining two wheels were modifications to this base wheel; either a 
plastic mesh or solid plastic strip was placed around the outside of the wheel so the mice still came in contact with the rods. In their preference test the mesh wheel was preferred over both the standard rod wheel and solid covered wheel. This preference of a plastic mesh wrapped wheel over standard rods was also apparent in their hamster study [58]. Golden hamsters and plastic mesh wheels were also used by Beaulieu and Reebs with the primary goal of studying paw wounds [5]. Those animals given a plastic mesh wheel ran $24 \%$ less than those with metal rods but a few crucial differences existed. Beaulieu and Reebs attached their plastic mesh to the inside of the wheel so the paws came into contact with it and only one wheel was placed in each cage. They attributed the reduced activity to an increased size and duration of paw wounds. The plastic mesh allowed more of the paw to come into contact each step compared to the rod alternative. These studies present an argument that wheel surface material does matter, specifically what is coming into contact with the animal's paws.

\subsection{Temperature}

Environmental factors such as temperature have been well documented with respect to physical activity performance in humans $[16,32,43,57]$. As already reported there are physiological similarities between mice and humans so therefore the study of temperature's effect on wheel running is valuable. High temperatures have been shown to increase and decrease activity levels in different animals so specificity is required when making hypotheses $[14,33,88]$.

Warm-blooded animals have internal mechanisms to control their body temperature across any range of ambient temperature they may encounter. At rest, hypothermia at low ambient temperatures is avoided by elevating metabolic rates, while decreasing metabolic 
rates at high temperatures occurs if environmental temperatures are elevated [57]. In the context of exercise, humans preserve this trend of temperature control in part to prevent injury and in part due to the physical limitations of the human body. In order to maintain an optimal homoeothermic environment, activity is decreased in hot temperatures to reduce endogenous heat production and the inverse happens in cold environments [16]. Vaanholt, et al. saw this trend reverse in both mice bred for high spontaneous wheel running activity and cage controls [88]. They hypothesized that the increased metabolic cost of thermoregulation at low ambient temperatures could be too great for high levels of activity, but had no explanation for the activity increase in high temperatures. Campbell and Lynch saw a similar trend in Sprague Dawley rats; activity was not reduced when body temperatures were raised above the preferred thermal neutral zone of 27 to $30^{\circ} \mathrm{C}$ [14]. Yet a trend similar to humans was seen by male Wistar rats; as ambient temperature increased, wheel running decrease [33]. While not completely resolved, the preponderance of evidence indicates that ambient temperature affects wheel running.

Based on the current literature, a variety of factors can alter PA levels in mice. Sex and strain have been widely studied with significant findings. Out of these studies researchers are able to choose optimal subjects to examine the effect of different types and sizes of wheels on affect activity levels. However studies with combinations of these factors often employ singly housed animals, which has been shown to modify physiological systems $[3,83]$. Therefore group housing is a possible option to negate this isolation effect, which is currently being underused in the field. Thus, the current study was designed to assess the impacts of housing density and wheel availability on physical activity levels in outbred SENCAR mice. 


\section{METHODS}

Overview: All procedures in this study were carried out according to federal regulations and after approval by the Texas A\&M Institutional Animal Care and Use Committee (AUP 2013-0132).

\subsection{Experimental Mice}

Six female SENCAR outbred mice were purchased from the National Cancer Institute (Frederick, MD) and randomly numbered S1 to S6. Female SENCAR mice were used as opposed to an inbred strain because the SENCAR strain (and females only) were being investigated in a larger project investigating the effect of dual housing, exercise, diet on mammary tumorigenesis. Further, female mice are more active than male mice [50].

After adequate acclamation time $(\approx 1$ week $)$, four mice were randomly assigned to cages with one mouse per cage (S1-4) and a single metal running wheel with a solid surface and a circumference of $450 \mathrm{~cm}$ was mounted in each cage. This single housing/ single wheel combination was designated as '1v1'. The remaining two mice (S5/S6) were housed together, also with one metal running wheel of the same dimensions; this double housing / single wheel combination was designated as ' $2 \mathrm{v} 1$ '.

The running wheels were securely affixed to the top of the cage in order to allow free turning of the wheel and sufficient room for the mice to enter and exit the wheel at will. Wheel running measurements and set-ups followed techniques previously published repeatedly by our lab group [50]. Briefly, magnets were glued to each wheel and Sigma Sport BC500 computers were placed on top of each cage in alignment with the glued magnets. These computers were calibrated to the running wheel size and distance $(\mathrm{km})$ and 
duration (mins) were recorded on a daily basis. Distance was subsequently divided by duration of exercise to calculate the speed $(\mathrm{m} / \mathrm{min})$ of exercise. With regard to the $2 \mathrm{v} 1$ condition and to any cage that housed two mice at a time, we were not able to distinguish the individual distances run by the mice in the cage, as data were recorded per wheel.

After four weeks under these housing conditions S5 and S6 were split up into 1v1 combinations and mice $\mathrm{S} 1$ and $\mathrm{S} 2$ were combined to form a $2 \mathrm{v} 1$ cage. This was done in order to compare mice that had been singly housed under the $2 \mathrm{v} 1$ condition. Two weeks later mice S3 and S4 were combined into a 2v1 cage - to further increase the sample size of this combination - while S5 and S6 remained in 1v1. After an additional two weeks, an apparent decrease in total cage activity in the $2 \mathrm{v} 1$ condition (see Fig. 1) was noted, which may have been caused by a lack of available wheels (i.e. both mice wanted to run at the same time). Thus, we introduced a third housing option, in which a second wheel of the same type was added to the cage, creating a two mouse-two wheel system, the $2 \mathrm{v} 2$ combination. The 2v2 option was introduced into the cages housing S1/S2 and S3/S4 mice while S5 and S6 mice remained in the $1 \mathrm{v} 1$ condition. These combinations $-1 \mathrm{v} 1$ and $2 \mathrm{v} 2-$ were then carried out for the remaining seven months of the study.

\subsection{Procedures}

Mice were housed in a fully climate controlled animal housing facility equipped with a 12:12 light dark cycle. Daily during the light cycle, between the hours of 6:00 AM and 6:00 PM, the distance and duration on each cage computer were manually recorded. Recording times were taken during a six hour window of the light cycle. Exact accuracy with time of recording was deemed a non-factor due to the general reduction of activity during the light cycle. Bi-monthly the data was entered into a computer spreadsheet in order 
to calculate daily distances, durations, and average running speeds. During daily recordings, the status of each wheel-running apparatus was assessed to assure that proper magnet-sensor alignment was maintained and wheels rotated properly. Data from periods in which the apparatus failed (e.g. magnet was chewed off, wheel came out of alignment, bedding was piled preventing wheel rotation) were removed. Days when housing density changed were also marked in the data book to insure proper data tracking could be continued.

\subsection{Statistics and Analysis}

Initial activity indices between 1v1 and 1v2 conditions were compared using a twoway ANOVA with week and housing condition as factors. The alpha value was set at $0.05 a$ priori. Post hoc analysis (Tukey) was conducted if significant main effects were observed. Overall differences between housing/wheel conditions were compared using a 1-way ANOVA with housing/wheel condition as the factor. Given that we could not determine how much activity each mouse in the double-housed wheels completed, the data was analyzed by wheel; i.e. cages with two wheels in them had activity values averaged within cage that resulted in two equivalent wheel values within each cage. The alpha value was set a priori at 0.05. Wheel preference analysis was conducted by averaging the activity index across the total time of observation in the animal groupings that had two wheels mounted in the cage (S1/S2 and S3/S4) and comparing these indices within cage. Thus, an overall comparison of

right vs. left-mounted wheels was determined using a paired t-test. The alpha value was set $a$ priori at 0.05 . Further analysis of wheel preference was conducted by subtracting daily distances, duration, and speed observed on the right wheel from the left wheel within each cage. These wheel preference differences were then fit with the equation that resulted in the best fit. To investigate potential factors increasing wheel running variance across the study, 
we randomly selected a 14 day period in which complete distance data was available for all animals (i.e. there were no wheel-malfunctions during this period). We compared the distance the animals ran between the housing conditions $1 \mathrm{v} 1$ and $2 \mathrm{v} 2 \mathrm{using}$ a one-way ANOVA with the alpha value set at 0.05 a priori. 


\section{RESULTS}

Figure 1 shows the running distances of the original experimental set up (1v1 vs.

$2 v 1)$. Values are represented per cage as opposed to per wheel because all cages had only one wheel. While time in these combinations is limited ( $n=24-28$ days), there was a significantly longer distance ran by the mice in the $1 \mathrm{v} 1$ cages overall $(\mathrm{p}<0.0001)$, specifically for weeks three and four $(\mathrm{p}<0.0001)$. It is important to note however that data for the $2 \mathrm{v} 1$ cage was limited to only three days during week four due to apparatus malfunction (i.e. magnet out of alignment or stuck wheel).

After these initial results, as indicated in the Methods, we converted the $2 \mathrm{v} 1$ groups to the $2 \mathrm{v} 2$ configuration with a second wheel. Figures 2-4 depict the three primary activity measurements (i.e. distance, duration, and speed) amongst all housing combinations over all days of observation. The numbers of days of observation varied because of the varying length of time of use of the housing/wheel condition as well as the number of data points eliminated due to malfunctioning wheels. Further, if there were not both valid distance and duration measures for a day, that day was eliminated from the analysis.

Thus, the days of observation used in the analysis for each condition were: $1 \mathrm{v} 1=506$ days of observation; $2 \mathrm{v} 1=64$ days of observation; and $2 \mathrm{v} 2=316$ days of observation. Overall, these data showed there was a significant effect of housing density and wheel availability on activity levels. Relative to daily distance, $2 \mathrm{v} 1$ and $2 \mathrm{v} 2$ cages ran significantly less $(\mathrm{p}=0.0001)$ per wheel than $1 \mathrm{v} 1$ cages (Fig. 2$)$. This decrease in daily distance between $1 \mathrm{v} 1$ and $2 \mathrm{v} 1$ cages is in agreement with the data shown in Figure 1, supporting our initial hypothesis. Likewise, daily duration ran per wheel in $2 \mathrm{v} 1$ cages was significantly less $(\mathrm{p}=$ 
$0.0001)$ than $1 \mathrm{v} 1$ cages, while $2 \mathrm{v} 2$ cages spent significantly less $(\mathrm{p}=0.0036)$ time running than both alternative housing options (Fig. 3). However 1v1 and 2v1 cages ran significantly slower $(\mathrm{p}=0.0001)$ than $2 \mathrm{v} 2$ cages (Fig. 4).

Mice S5 and S6 were housed in a 1v1 combination for the longest amount of time leading us to use their data to produce Figure 5. Panels (a) and (b) present the daily distances ran by these mice caged as indicated for 3 to 10 months of age. In both panels of Fig. 5, the periodicity of daily distances ran is marked by a low day, two rising days, and a final peak day to complete the four day cycle. This rhythm has been previously established to be driven by the estrous cycle [68]. The second trend seen in these figures is the increase and decrease in wheel activity relative to age. While the saw tooth pattern is still present in the latter half of the data set, both the peak and low days are decreased in magnitude compared to values recorded earlier in the lifespan of the mice. These data agree with the current literature showing a decrease of activity in aging mice [87] as well as the estrous cycle-induced periodicity of activity [68].

Figures 6-8 depict the lifetime total distance, duration, and average speed covered on the left and right wheels from S1/S2 (a) and S3/S4 (b) while housed in $2 \mathrm{v} 2$ cages. As previously established both wheels were the same size, consisted of the same material, and attached to the cage in the same fashion. The experiment was designed to avoid, as much as possible, introduction of any bias. As shown in Figures 6-8, increased preference of mice in both cages for the left over the right wheel was observed, and this preference reached significance for distance $(\mathrm{p}<0.0001)$, duration $(\mathrm{p}<0.001)$, and speed $(\mathrm{p}<0.0081)$. While the distance run on the left wheel was significantly longer for both S1/S2 and S3/S4 cages, the preference in duration was primarily due to the S3/S4 cage (Figure 7). Further, the 
increased speed achieved with the left wheel, while statistically significant, was quite variable over the course of the experiment (Fig. 8) and thus, is of unknown physiological relevance.

These analyses, Figures 6-8, used the cumulative distance and duration measurements from the cage computers. In order to determine if this left-right preference changed over time the daily difference between wheels for distance, duration, and speed within each cage was analyzed (Fig. 9-11). Figure 9 shows the daily difference in distance per wheel from $\mathrm{S} 1 / \mathrm{S} 2$ (a) and S3/S4 (b) while housed in 2v2 cages. As depicted in panel (a), cage S1/S2 showed decreased left wheel preference over time $(\mathrm{p}<0.0001)$. These data produced a poor linear fit $\left(r^{2}=0.15\right)$. Daily distance between wheels in cage S3/S4 showed no significant difference along with a poor linear fit $\left(\mathrm{p}=0.4664, \mathrm{r}^{2}=0.0031\right)$. Figure 10 presents duration values for the same groups and parameters. Cage S1/S2 showed slight left wheel preference initially but trended toward the right wheel overtime. However more time was still spent on the left wheel, reaching statistical significance $\left(p=0.0062, r^{2}=0.05\right)$. Similar to the distance data, cage $\mathrm{S} 3 / \mathrm{S} 4$ showed no significant duration difference between wheels over time ( $\mathrm{p}=$ $0.9287, r^{2}=0.000047$ ). While both cages produced significant fits for speed (Figure 11, $\mathrm{p}<$ $0.0001)$, the physiological relevance of these data is suspect due to the poor fits $\left(r^{2}=0.1967\right.$, $r^{2}=0.1235$, respectively).

In order to assess a potential cause of the large variance seen in many of our analyses, a randomly picked 14 day period with complete data sets (e.g. distance, duration, speed) was chosen for more detailed comparisons of the distance ran in the 1v1 and $2 \mathrm{v} 2$ configurations (Fig 12). Using this 14-day period taken at $\sim 7$ months of age, differences in activity due to aging should be eliminated from calculation, leaving the effects of estrous cycle. We 
observed no significant difference $(\mathrm{p}=0.067)$ between distances ran in 1v1 and $2 \mathrm{v} 2$ cages during this two-week period. Further, we observed that while the standard deviations were smaller than those seen in the overall comparisons (Fig. 2), they were still approximately twice as large in the $2 \mathrm{v} 2$ condition as it was in the $1 \mathrm{v} 1$ condition; a similar proportionality in standard deviation was also present in the overall data. 


\section{DISCUSSION}

The aim of this study was to compare how various factors, principally housing density and wheel availability would affect physical activity levels in outbred SENCAR mice. With a standard $1 \mathrm{v} 1$ housing combination, the average daily distance ran by these mice was close to, or slightly more, than inbred mice labeled as "high active" [24, 28, 50]. Relative to this housing method, our data would place the SENCAR strain in the top 15\% in daily distance ran for mouse strains as established by Lightfoot et al. [50].

The SENCAR mice were chosen for the mammary tumorigenesis experiments because of the increased sensitivity to carcinogen [18, 29, 67], having been shown to be 10 to 20 times more sensitive to tumor initiation than CD-1 control mice [77]. Our voluntary wheel running model provides novel activity data with respect to outbred mice in general, and the SENCAR strain in particular.

Mice and other rodents are generally nocturnal, and the majority of their running is done at night $[37,41,79]$; however we observed running tendencies during the light cycle in response to daily tasks. When situations required the temporary removal of a wheel (e.g. damaged wheel replacement, computer realignment) the mice often would have to be physically removed from the wheel with clear resistance to this act. Upon reintroduction of the wheel the mice would immediately enter and begin running. This tendency was more apparent in the higher active cages but could be seen throughout the study across all animals.

Based on the 1v1 activity levels seen in this strain, we anticipated that there would be a decreased activity in the $2 \mathrm{v} 1$ combination due to competition for the wheel or higher levels of play outside the wheel. Indeed, our early results (Fig. 1) showed that the $2 \mathrm{v} 1$ animals were less active. This trend held throughout the entirety of the study; mice in 2v1 cages ran 
significantly shorter distances and for less time, compared to $1 \mathrm{v} 1$ cages. These results lead us to propose that the mice could be competing for time on the wheel. However, with the addition of a second wheel to avoid this competition, distance and duration actually went down, and only speed/day increased. When comparing the $2 \mathrm{v} 1$ and $2 \mathrm{v} 2$ configurations, distance in $2 \mathrm{v} 2$ cages was not different from $2 \mathrm{v} 1$ while duration actually decreased.

The addition of a cage mate altered total wheel running more than wheel availability. A potential mechanism underlying this decreased activity could be linked to increased cage activity outside of the wheel. Supporting this speculation is our anecdotal observations that during daily recordings often one mouse was seen entering a wheel to run which was shortly followed by the second mouse jumping on the same wheel. At first this observation might be seen as a mechanism to increase activity yet this attempt to simultaneously run, seen in both $2 \mathrm{v} 1$ and $2 \mathrm{v} 2$ cages, quickly lead to both mice falling off the wheel. After this occurrence the mice often continued to play/chase each other around the cage. The addition of a cage mate most likely increased total ambulatory activity but decreased activity on the wheel. This occurrence was observed during the light cycle, when activity is minimal, so further studies are necessary to elucidate what occurred during the dark cycle.

In high active inbred strains (e.g. C57L/J, [50]), normal variance in female mice during the high active period (9-12 weeks of age) is approximately $2.7 \mathrm{~km} /$ day. However we saw variances of 3.35-4.02 km/day across all housing combinations, leading to the conclusion that there are several potential factors responsible for the high level of variability observed in this study: 1) the mice used were an outbred strain with increased genetic heterogeneity; 2) PA was measured over a seven-month period, and it is well-established that activity levels decrease significantly across the lifespan in mice [87]; and 3) Part of the 
observed variability also could be due to the effect of the estrous cycle on activity in the mice. All mice were female and ran from six weeks to 10 months of age. Therefore the PA was initiated in the prepubertal period, and continued into sexual adulthood, including the well documented peak activity period (9-12 weeks of age) [82] as well as the period of reduced activity associated with aging [87], as observed in Fig. 5.

While our protocol was not designed to study wheel choice preference by the mice, some preference was surprisingly observed. All wheels used in this study were constructed of identical solid metal, with a circumference of $450 \mathrm{~mm}$. Therefore, there was no innate difference between the wheels in the $2 \mathrm{v} 2$ combination other than location within the cage, yet significant preference was seen for the left wheel across all major variables (i.e. distance, Fig. 6; duration, Fig. 7; and speed, Fig. 8). Due to the limitations of the design we cannot determine the individual distances run by each mouse, only how much each wheel was being used.

The 2v2 cages averaged five hours of running on each wheel per night, totaling ten hours per cage. Based on being active primarily during the 12 hour dark cycle, and allotting time for lifestyle tasks (e.g. sleeping, eating, nest building), it seems highly unlikely that these activity levels were accomplished without the wheels being used at the same time. Additionally, while the speed index (Fig. 8) was noted to be significantly higher for the left wheel, upon examination of the patterns, it can be seen that this was variable and in fact, when considering how much difference in speed there was between the two wheels on a daily basis (Fig. 11) these differences appear to not be physiologically significant. The same can be said for the results depicted in Figures 9 and 10. While cage S3/S4 showed a daily preference for the left wheel, the fit was poor and significant was not reached. Adding in the 
variable preference seen in cage $\mathrm{S} 1 / \mathrm{S} 2$, increased right wheel preference overtime, it is difficult to make a solid claim for these data. Thus, while there were significant differences across all metrics between the wheels within each cage, with the left wheel generally being preferred, it is unclear as to the physiological relevance of these observations.

The act of learning acquisition could play a role in the root of this wheel preference. Spatial learning occurs via specialized place cells in the hippocampus, a different pathway than other types of learning [47]. Extinction of a learned task leads to suppression rather than a complete removal [47]. Therefore with reference to our mice, the initial left wheel preference seen in Figures 9 and 10a could potentially be brought back with proper training. Amongst other comparisons, Rogers et al. determined that spatial preference was related to lateral paw preference, a measure of 'handedness' in mice [71]. Multiple studies link these various preference tests to dopamine levels and associated arousal $[31,71,93]$. Of these papers, Glick et al. showed a link in rats between dopamine imbalances and spontaneous rotation within the cage [31]. Combining these variables together depicts an argument for the amount of circulating dopamine, which along with wheel activity is highest during the dark cycle $[71,79]$, leading to the learned preference of one wheel over the other. 


\section{SUMMARY}

In conclusion, various factors such as strain, housing density, and number of available wheels can alter wheel-running in mice. Until this study, wheel running had not been studied in outbred SENCAR mice. Our study shows that when compared to PA data from other strains, SENCARs would be considered highly active mice. Further, we observed the expected periodicity reflecting the estrous cycle in our SENCAR female mice that were provided voluntary wheel access for an extended period of time. Additionally, the housing of two mice in the same cage significantly decreased activity levels, regardless of wheel number. The observed decrease in distance can be primarily attributed to decreased time spent running, as the speed of exercise actually increased when 2 animals were co-caged. Surprisingly, we observed that mice housed with two wheels showed a preference for exercise on the left wheel; this preference was unexpected and it is unknown why mice may have a preference. Therefore, our study illustrates that these variables must be considered in order to maintain the ability to translate conclusions to human application for activity based health interventions. 


\section{REFERENCES}

1. $\quad$ Allen, D.L., et al., Cardiac and skeletal muscle adaptations to voluntary wheel running in the mouse. Journal of Applied Physiology, 2001. 90(5): p. 1900-1908.

2. Anantharaman-Barr, H.G. and J. Decombaz, The effect of wheel running and the estrous cycle on energy expenditure in female rats. Physiology \& Behavior, 1989. 46(2): p. 259-263.

3. Banjanin, S. and N. Mrosovsky, Preferences of mice, Mus musculus, for different types of running wheel. Laboratory Animals, 2000. 34(3): p. 313-318.

4. Bauman, A.E., et al., Correlates of physical activity: why are some people physically active and others not? The Lancet, 2012. 380(9838): p. 258-271.

5. Beaulieu, A. and S. Reebs, Effects of bedding material and running wheel surface on paw wounds in male and female Syrian hamsters. Laboratory animals, 2009. 43(1): p. 85-90.

6. Billat, V.L., et al., Inter-and intrastrain variation in mouse critical running speed. Journal of Applied Physiology, 2005. 98(4): p. 1258-1263.

7. Billingslea, F., The relationship between emotionality, activity, curiosity, persistence and weight in the male rat. Journal of Comparative Psychology, 1940. 29(3): p. 315.

8. Blomqvist, C.G. and B. Saltin, Cardiovascular adaptations to physical training. Annual Review of Physiology, 1983. 45(1): p. 169-189.

9. Booth, F.W., M.J. Laye, and M.D. Roberts, Lifetime sedentary living accelerates some aspects of secondary aging. Journal of Applied Physiology, 2011. 111(5): p. 1497-1504.

10. Bouchard, C., et al., Familial aggregation of $V^{*}$ o 2 max response to exercise training: results from the HERITAGE Family Study. Journal of Applied Physiology, 1999. 87(3): p. 1003-1008.

11. Bowen, R., A. Hamilton, and J. Lightfoot, Pharmacological manipulation of the dopaminergic system affects wheel-running activity in differentially active mice. Journal of Biological Regulators and Homeostatic Agents, 2012. 26(1): p. 119.

12. Bowen, R.S., M.J. Turner, and J.T. Lightfoot, Sex hormone effects on physical activity levels. Sports Medicine, 2011. 41(1): p. 73-86.

13. Brown, J.D., S.P. Naples, and F.W. Booth, Effects of voluntary running on oxygen consumption, $R Q$, and energy expenditure during primary prevention of diet-induced obesity in C57BL/6N mice. Journal of Applied Physiology, 2012. 113(3): p. 473-478. 
14. Campbell, B.A. and G.S. Lynch, Influence of hunger and thirst on the relationship between spontaneous activity and body temperature. Psychol, 1968. 65: p. 492-498.

15. Carmody, T.P., et al., Physical exercise rehabilitation: Long-term dropout rate in cardiac patients. Journal of Behavioral Medicine, 1980. 3(2): p. 163-168.

16. Cheuvront, S. and E. Haymes, Thermoregulation and marathon running. Sports Medicine, 2001. 31(10): p. 743-762.

17. Church, D.M., et al., Lineage-specific biology revealed by a finished genome assembly of the mouse. PLOS Biology, 2009. 7(5): p. e1000112.

18. Coghlan, L.G., et al., Development and initial characterization of several new inbred strains of SENCAR mice for studies of multistage skin carcinogenesis.

Carcinogenesis, 2000. 21(4): p. 641-646.

19. Coleman, K.J. and D.R. Rager, Effects of voluntary exercise on immune function in rats. Physiology \& Behavior, 1993. 54(4): p. 771-774.

20. Collier, G. and E. Hirsch, Reinforcing properties of spontaneous activity in the rat. Journal of Comparative and Physiological Psychology, 1971. 77(1): p. 155.

21. Collier, G. and A.I. Leshner, An invariant in mouse running wheel behavior. Psychonomic science, 1967. 8(1): p. 9-10.

22. Davidson, S.R., M. Burnett, and L. Hoffman-Goetz, Training effects in mice after long-term voluntary exercise. Medicine and Science in Sports and Exercise, 2006. 38(2): p. 250-255.

23. Dishman, R.K., W. Ickes, and W.P. Morgan, Self-motivation and adherence to habitual physical activity. Journal of Applied Social Psychology, 1980. 10(2): p. 115-132.

24. Dumke, C., et al., Genetic selection of mice for high voluntary wheel running: effect on skeletal muscle glucose uptake. Journal of Applied Physiology, 2001. 91(3): p. 1289-1297.

25. Eikelboom, R. and R. Mills, A microanalysis of wheel running in male and female rats. Physiology \& Behavior, 1988. 43(5): p. 625-630.

26. Farmer, J., et al., Effects of voluntary exercise on synaptic plasticity and gene expression in the dentate gyrus of adult male Sprague-Dawley rats in vivo. Neuroscience, 2004. 124(1): p. 71-79.

27. Ferguson, D.P., et al., Differential skeletal muscle proteome of high-and low-active mice. Journal of Applied Physiology, 2014. 116(8): p. 1057-1067. 
28. Festing, M.F., Wheel activity in 26 strains of mouse. Laboratory Animals, 1977. 11(4): p. 257-258.

29. Gimenez-Conti, I., et al., Dissociation of sensitivities to tumor promotion and progression in outbred and inbred SENCAR mice. Cancer Research, 1992. 52(12): p. 3432-3435.

30. Gladfelter, W.E. and J.R. Brobeck, Decreased spontaneous locomotor activity in the rat induced by hypothalamic lesions. American Journal of Physiology--Legacy Content, 1962. 203(5): p. 811-817.

31. Glick, S.D. and R.D. Cox, Nocturnal rotation in normal rats: correlation with amphetamine-induced rotation and effects of nigro-striatal lesions. Brain Research, 1978. 150(1): p. 149-161.

32. González-Alonso, J., C.G. Crandall, and J.M. Johnson, The cardiovascular challenge of exercising in the heat. The Journal of Physiology, 2008. 586(1): p. 4553.

33. Gutiérrez, E., et al., High ambient temperature reduces rate of body-weight loss produced by wheel running. The Quarterly Journal of Experimental Psychology, 2006. 59(7): p. 1196-1211.

34. Hoppeler, H., et al., Endurance training in humans: aerobic capacity and structure of skeletal muscle. Journal of Applied Physiology, 1985. 59(2): p. 320-327.

35. Horwitz, J.R., B.D. Kelly, and J.E. DiNardo, Wellness incentives in the workplace: cost savings through cost shifting to unhealthy workers. Health Affairs, 2013. 32(3): p. 468-476.

36. Houle-Leroy, P., et al., Effects of voluntary activity and genetic selection on muscle metabolic capacities in house mice Mus domesticus. Journal of Applied Physiology, 2000. 89(4): p. 1608-1616.

37. Johnson, M.S., Activity and distribution of certain wild mice in relation to biotic communities. Journal of Mammalogy, 1926. 7(4): p. 245-277.

38. Jones, L., W. Bellingham, and L. Ward, Sex differences in voluntary locomotor activity of food-restricted and ad libitum-fed rats. Implications for the maintenance of a body weight set-point. Comparative Biochemistry and Physiology Part A: Physiology, 1990. 96(2): p. 287-290.

39. Joosen, A.M., et al., Genetic analysis of physical activity in twins. The American Journal of Clinical Nutrition, 2005. 82(6): p. 1253-1259.

40. Kaplan, M.L., et al., Cardiac adaptations to chronic exercise in mice. American Journal of Physiology-Heart and Circulatory Physiology, 1994. 267(3): p. H1167H1173. 
41. Kavanau, J.L., Behavior of captive white-footed mice. Science, 1967. 155(3770): p. 1623-1639.

42. Kemi, O.J., et al., Intensity-controlled treadmill running in mice: cardiac and skeletal muscle hypertrophy. Journal of Applied Physiology, 2002. 93(4): p. 1301-1309.

43. Kenney, W.L., et al., Blood pressure regulation III: what happens when one system must serve two masters: temperature and pressure regulation? European Journal of Applied Physiology, 2014. 114(3): p. 467-479.

44. Knab, A.M. and J.T. Lightfoot, Does the difference between physically active and couch potato lie in the dopamine system? International Journal of Biological Sciences, 2010. 6(2): p. 133.

45. Konhilas, J.P., et al., Loaded wheel running and muscle adaptation in the mouse. American Journal of Physiology-Heart and Circulatory Physiology, 2005. 289(1): p. H455-H465.

46. Landisch, R.M., et al., Adaptive and nonadaptive responses to voluntary wheel running by mdx mice. Muscle \& Nerve, 2008. 38(4): p. 1290-1293.

47. Lattal, K.M., M.T. Mullen, and T. Abel, Extinction, renewal, and spontaneous recovery of a spatial preference in the water maze. Behavioral Neuroscience, 2003. 117(5): p. 1017-1028.

48. Laye, M.J., et al., Inactivity induces increases in abdominal fat. Journal of applied physiology, 2007. 102(4): p. 1341-1347.

49. LeMura, L.M. and M.T. Maziekas, Factors that alter body fat, body mass, and fatfree mass in pediatric obesity. Medicine and Science in Sports and Exercise, 2002. 34(3): p. 487-496.

50. Lighfoot, J.T., et al., Strain screen and haplotype association mapping of wheel running in inbred mouse strains. Journal of Applied Physiology, 2010.

51. Lightfoot, J.T., et al., Genetic influence on daily wheel running activity level. Physiological genomics, 2004. 19(3): p. 270-276.

52. Lightfoot, J.T., et al., Quantitative trait loci for physical activity traits in mice. Physiological Genomics, 2008. 32(3): p. 401-408.

53. McLaughlin, R. and G. Wittert, The obesity epidemic: implications for recruitment and retention of defence force personnel. Obesity Reviews, 2009. 10(6): p. 693-699.

54. Meijer, J.H. and Y. Robbers, Wheel running in the wild. The Proceedings of the Royal Society, 2014. 281(1786). 
55. Mokdad, A.H., et al., Actual causes of death in the United States, 2000. The Journal of the American Medical Association, 2004. 291(10): p. 1238-1245.

56. Mokdad, A.H., et al., The spread of the obesity epidemic in the United States, 19911998. The Journal of the American Medical Association, 1999. 282(16): p. 15191522.

57. Mount, L., Basis of heat regulation in homoeotherms. British Medical Bulletin, 1966. 22(1): p. 84-87.

58. Mrosovsky, N., P.A. Salmon, and N. Vrang, Revolutionary science: an improved running wheel for hamsters. Chronobiology International, 1998. 15(2): p. 147-158.

59. Must, A., et al., The disease burden associated with overweight and obesity. The Journal of the American Medical Association, 1999. 282(16): p. 1523-1529.

60. Myers, J., Exercise and cardiovascular health. Circulation, 2003. 107(1): p. e2-e5.

61. Novak, C.M., P.R. Burghardt, and J.A. Levine, The use of a running wheel to measure activity in rodents: relationship to energy balance, general activity, and reward. Neuroscience \& Biobehavioral Reviews, 2012. 36(3): p. 1001-1014.

62. Oldridge, N.B., Compliance and exercise in primary and secondary prevention of coronary heart disease: a review. Preventive Medicine, 1982. 11(1): p. 56-70.

63. Owen, N., et al., Environmental determinants of physical activity and sedentary behavior. Exercise and Sport Sciences Reviews, 2000. 28(4): p. 153-158.

64. Pérusse, L., et al., Genetic and environmental influences on level of habitual physical activity and exercise participation. American Journal of Epidemiology, 1989. 129(5): p. 1012-1022.

65. Ponting, C. and L. Goodstadt, Separating derived from ancestral features of mouse and human genomes. Biochemical Society Transactions, 2009. 37(4): p. 734.

66. Premack, D. and R.W. Schaeffer, Some parameters affecting the distributional properties of operant-level running in rats. Journal of the Experimental Analysis of Behavior, 1963. 6(3): p. 473-475.

67. Qing, W.-G., et al., Induction of mammary cancer and lymphoma by multiple, low oral doses of 7, 12-dimethylbenz [a] anthracene in SENCAR mice. Carcinogenesis, 1997. 18(3): p. 553-559.

68. Richter, C.P., Animal behavior and internal drives. The Quarterly Review of Biology, 1927. 2(3): p. 307-343.

69. Roberts, M.D., et al., Phenotypic and molecular differences between rats selectively bred to voluntarily run high vs. low nightly distances. American Journal of 
Physiology-Regulatory, Integrative and Comparative Physiology, 2013. 304(11): p. R1024-R1035.

70. $\quad$ Roberts, M.D., et al., Dopamine D1 receptor modulation in nucleus accumbens lowers voluntary wheel running in rats bred to run high distances. Physiology \& Behavior, 2012. 105(3): p. 661-668.

71. Rogers, T.T. and M.B. Bulman-Fleming, Arousal mediates relations among medial paw preference, lateral paw preference, and spatial preference in the mouse.

Behavioural Brain Research, 1998. 93(1): p. 51-62.

72. Rowland, T.W., The biological basis of physical activity. Medicine and Science in Sports and Exercise, 1998. 30(3): p. 392-399.

73. S Banjanin, N.M., Preferences of mice, Mus musculus, for different types of running wheel. Laboratory Animals, 2000. 34: p. 313-318.

74. Sciolino, N.R. and P.V. Holmes, Exercise offers anxiolytic potential: a role for stress and brain noradrenergic-galaninergic mechanisms. Neuroscience \& Biobehavioral Reviews, 2012. 36(9): p. 1965-1984.

75. Sherwin, C., Voluntary wheel running: a review and novel interpretation. Animal Behaviour, 1998. 56(1): p. 11-27.

76. Shirley, M., Studies in activity. II. Activity rhythms; age and activity; activity after rest. Journal of Comparative Psychology, 1928. 8(2): p. 159.

77. Slaga, T.J., SENCAR mouse skin tumorigenesis model versus other strains and stocks of mice. Environmental Health Perspectives, 1986. 68: p. 27.

78. Späni, D., et al., Higher heart rate of laboratory mice housed individually vs in pairs. Laboratory Animals, 2003. 37(1): p. 54-62.

79. Stewart, C.C., Variations in daily activity produced by alcohol and by changes in barometric pressure and diet, with a description of recording methods. American Journal of Physiology--Legacy Content, 1898. 1(1): p. 40-56.

80. Stranahan, A.M., D. Khalil, and E. Gould, Social isolation delays the positive effects of running on adult neurogenesis. Nature Neuroscience, 2006. 9(4): p. 526533.

81. Suzuki, K., K. Machida, and M. Kariya, [Conditions for low-intensity voluntary wheel running in rats and its chronic effects on health indexes]. Japanese Journal of Hygiene, 1992. 47(5): p. 939-951.

82. Swallow, J.G., et al., Effects of voluntary activity and genetic selection on aerobic capacity in house mice (Mus domesticus). Journal of Applied Physiology, 1998. 84(1): p. 69-76. 
83. Swallow, J.G., et al., Artificial selection for increased wheel-running activity in house mice results in decreased body mass at maturity. Journal of Experimental Biology, 1999. 202(18): p. 2513-2520.

84. Syme, D.A., et al., Contractile abilities of normal and "mini" triceps surae muscles from mice (Mus domesticus) selectively bred for high voluntary wheel running. Journal of Applied Physiology, 2005. 99(4): p. 1308-1316.

85. Tran, B.X., et al., Cost analyses of obesity in Canada: scope, quality, and implications. Cost Effective Resource Allocation, 2013. 11(3).

86. Troiano, R.P., et al., Physical activity in the United States measured by accelerometer. Medicine and Science in Sports and Exercise, 2008. 40(1): p. 181.

87. Turner, M.J., S.R. Kleeberger, and J.T. Lightfoot, Influence of genetic background on daily running-wheel activity differs with aging. Physiological genomics, 2005. 22(1): p. 76-85.

88. Vaanholt, L.M., et al., Wheel-running activity and energy metabolism in relation to ambient temperature in mice selected for high wheel-running activity. Journal of Comparative Physiology B, 2007. 177(1): p. 109-118.

89. Van Praag, H., et al., Running enhances neurogenesis, learning, and long-term potentiation in mice. Proceedings of the National Academy of Sciences, 1999. 96(23): p. 13427-13431.

90. Van Praag, H., G. Kempermann, and F.H. Gage, Running increases cell proliferation and neurogenesis in the adult mouse dentate gyrus. Nature Neuroscience, 1999. 2(3): p. 266-270.

91. Vihko, V., A. Salminen, and J. Rantamaki, Exhaustive exercise, endurance training, and acid hydrolase activity in skeletal muscle. Journal of Applied Physiology, 1979. 47(1): p. 43-50.

92. Voelker, R., Escalating obesity rates pose health, budget threats. The Journal of the American Medical Association, 2012. 308(15): p. 1514-1514.

93. Whishaw, I.Q., W.T. O'connor, and S.B. Dunnett, The contributions of motor cortex, nigrostriatal dopamine and caudate-putamen to skilled forelimb use in the rat. Brain, 1986. 109(5): p. 805-843.

94. Wyatt, S.B., K.P. Winters, and P.M. Dubbert, Overweight and obesity: prevalence, consequences, and causes of a growing public health problem. The American Journal of the Medical Sciences, 2006. 331(4): p. 166-174. 


\section{APPENDIX A}

Fig. 1 - Average Weekly Distance per Cage

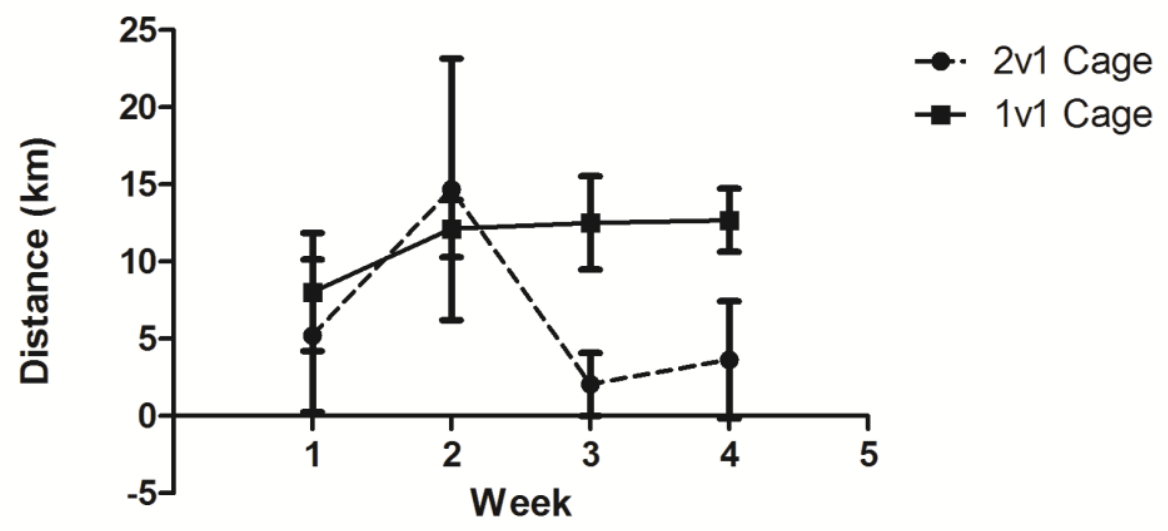

Figure 1 - Average weekly distance per cage with two housing combinations. 1v1 Cage is significantly higher than $2 \mathrm{v} 1$ ( $p<0.0001)$. Additionally, $1 \mathrm{v} 1$ is higher at week $3 \& 4(p<0.0001)$ 
Fig. 2 - Average Daily Distance per Wheel

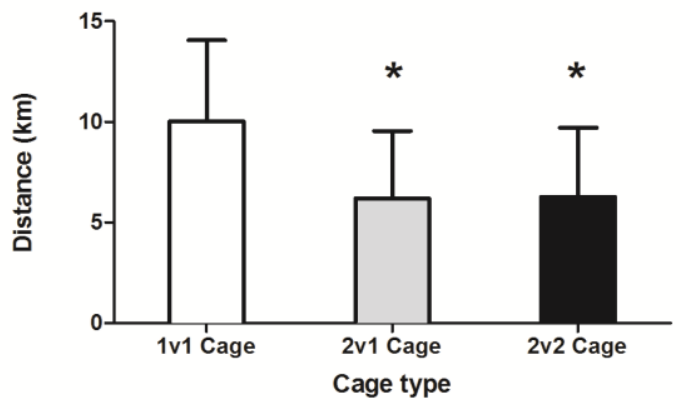

Figure 2 - Average daily distance per wheel with various mouse and wheel numbers.

* Denotes significant difference $(p=0.001)$ from $1 \mathrm{v} 1$ housing.

Fig. 3 - Average Daily Duration per Wheel

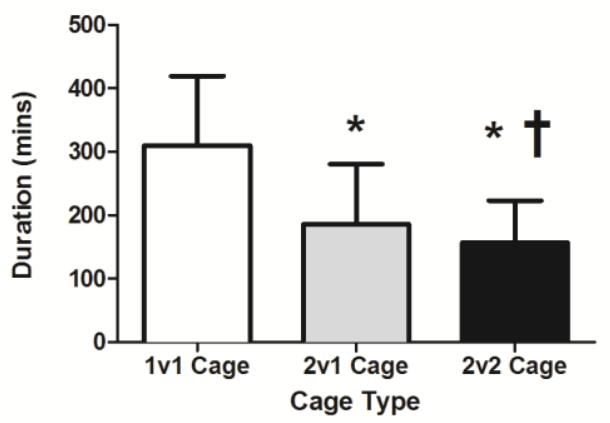

Figure 3 - Average daily duration per wheel with various mouse and wheel numbers. * Denotes significant difference $(p=0.001)$ from $1 \mathrm{v} 1$ housing;

$\dagger$ denotes significant difference $(p=0.0036)$ from $2 \mathrm{v} 1$ housing.

Fig. 4 - Average Daily Speed per Wheel

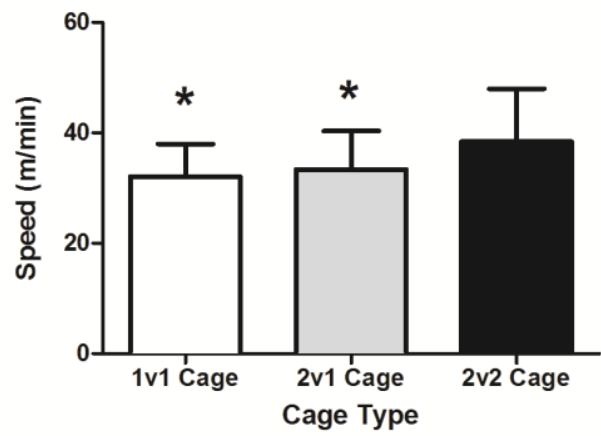

Figure 4 - Average daily speed per wheel with various mouse and wheel numbers. * Denotes significant difference $(p=0.0001)$ from $2 \sqrt{ } 2$ housing. 


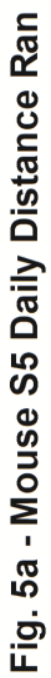

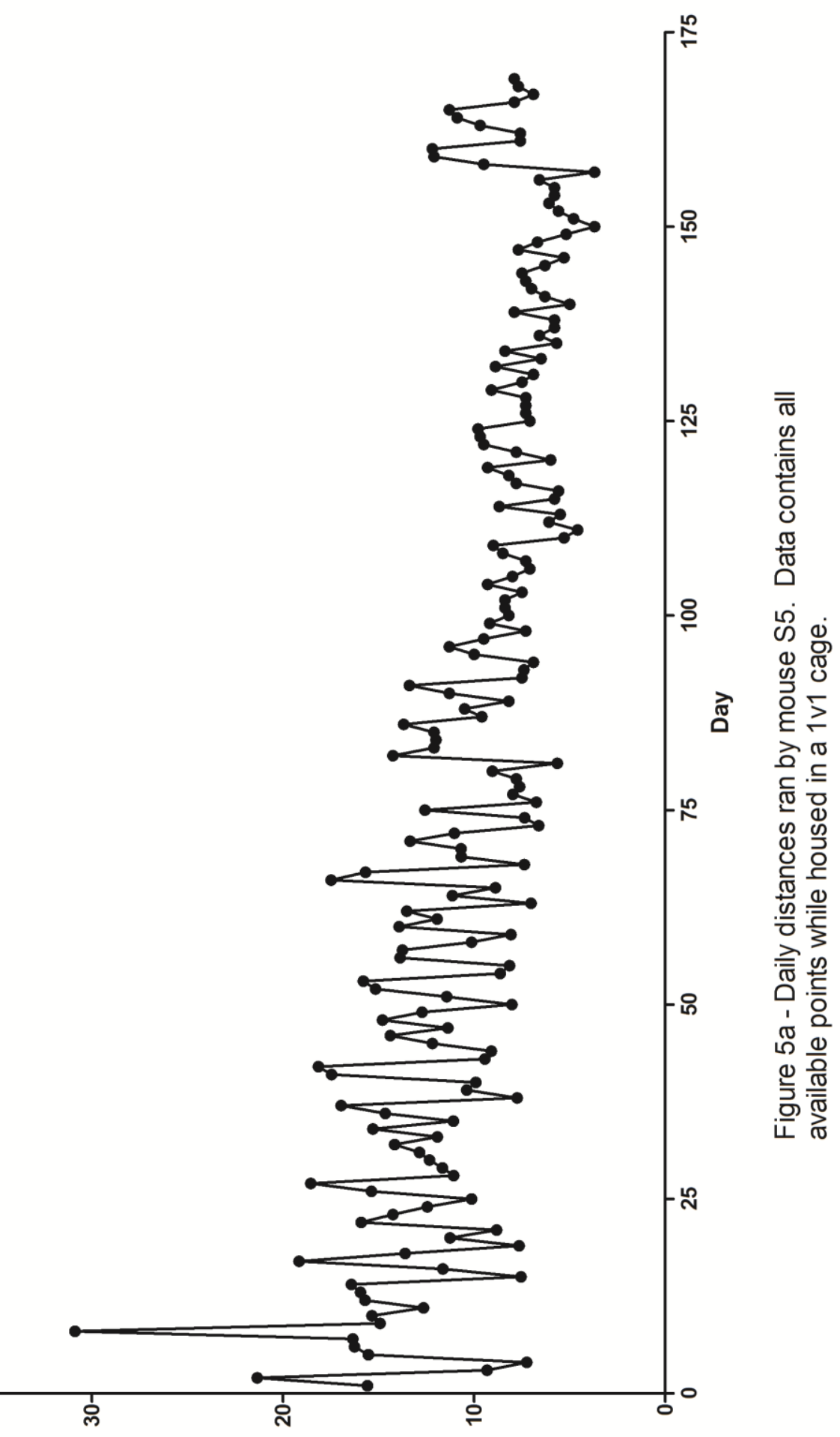

(шу) әэuełs! 


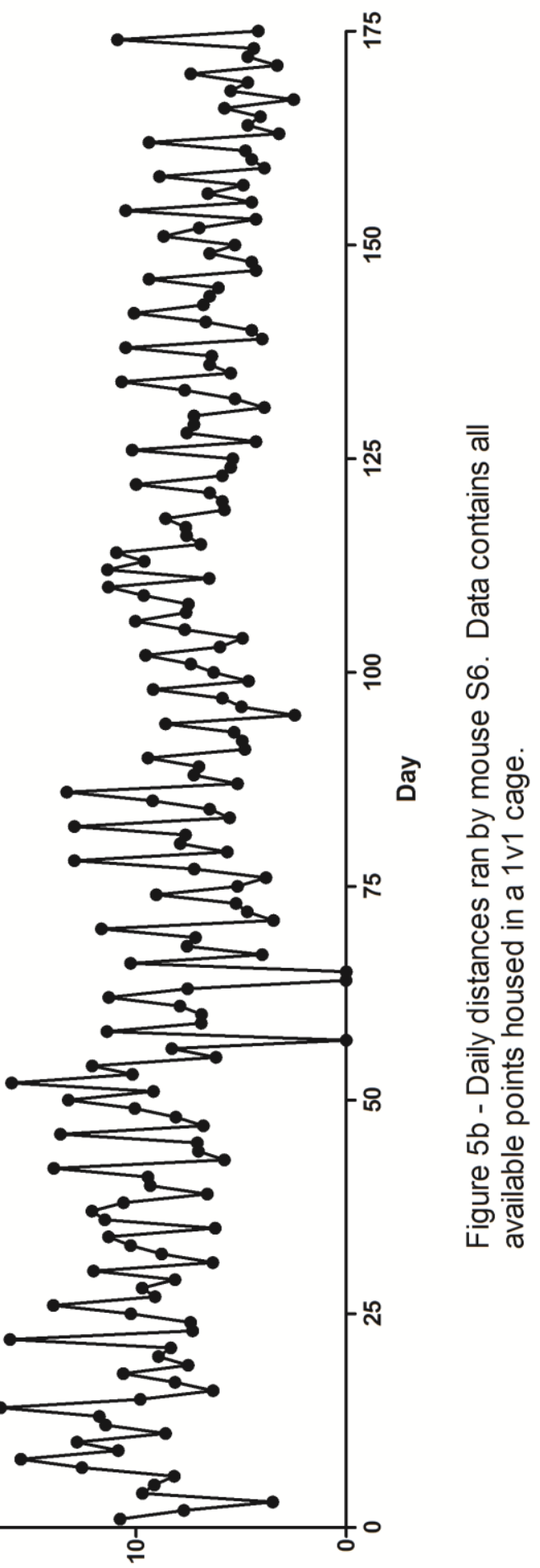

(uу) әэuеłs! 
Fig. 6 a,b - Mice S1/S2 and S3/S4

\section{Total Distance per Wheel}
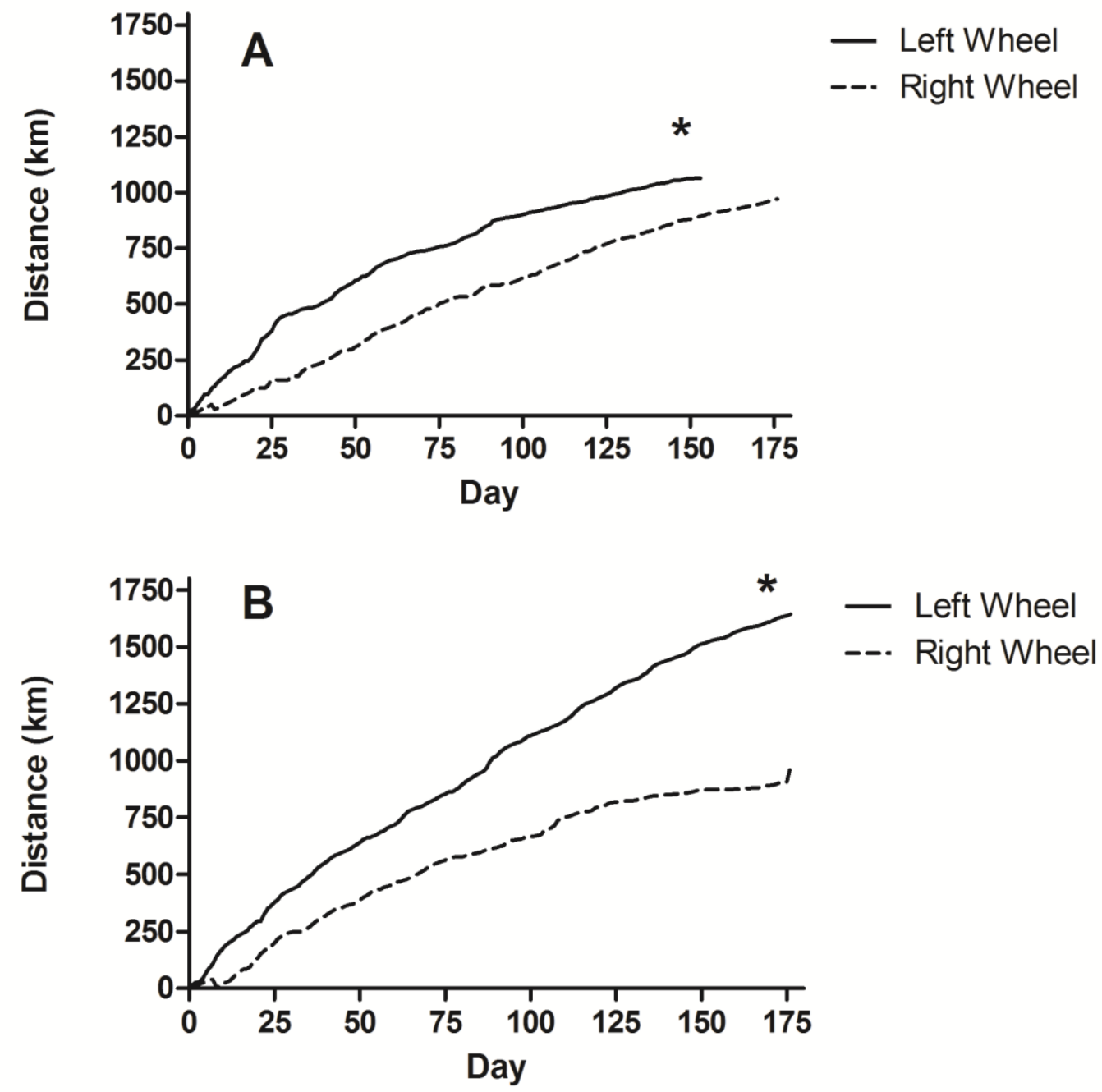

Figure 6 a,b - Total distance ran per wheel by mice S1/S2 (a) and S3/S4 (b). Data contains all available points while animals were housed in $2 \mathrm{v} 2$ cages. There was a significant preference $(p<0.0001)$ for the left wheel over the right wheel in both cages. * Denotes significance difference between wheels. 
Fig. 7 a,b - Mice S1/S2 and S3/S4 Total Time per Wheel
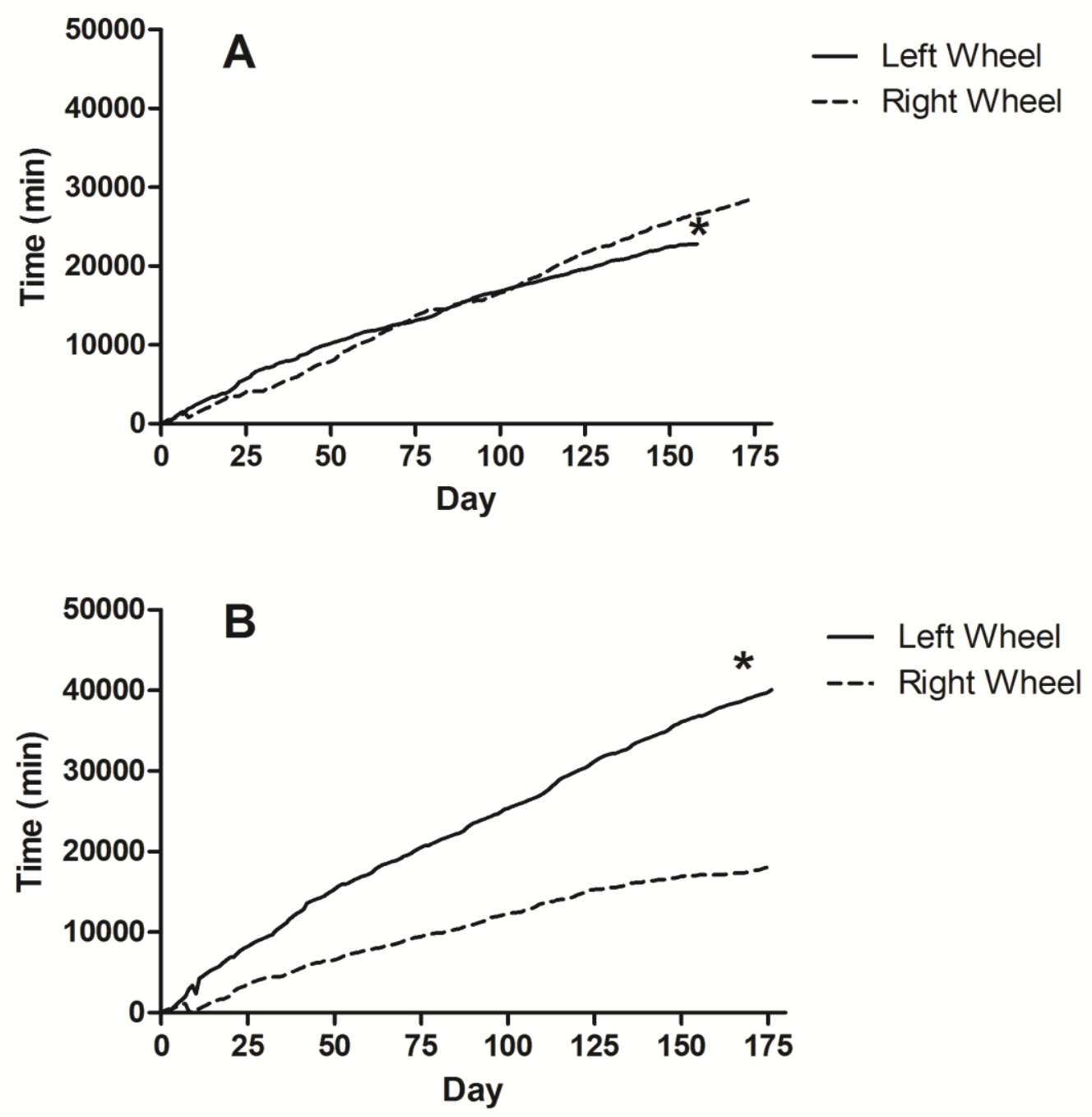

Figure $7 \mathrm{a}, \mathrm{b}$ - Average daily speed per wheel by mice S1/S2 (a) and S3/S4 (b). Data contains all available points while animals were housed in $2 \mathrm{v} 2$ cages. There was a significant preference $(p<0.0001)$ for the left wheel over the right wheel in both cages. * Denotes significant difference betweel wheels. 
Fig. 8 a,b - Mice S1/S2 and S3/S4

Average Daily Speed per Wheel
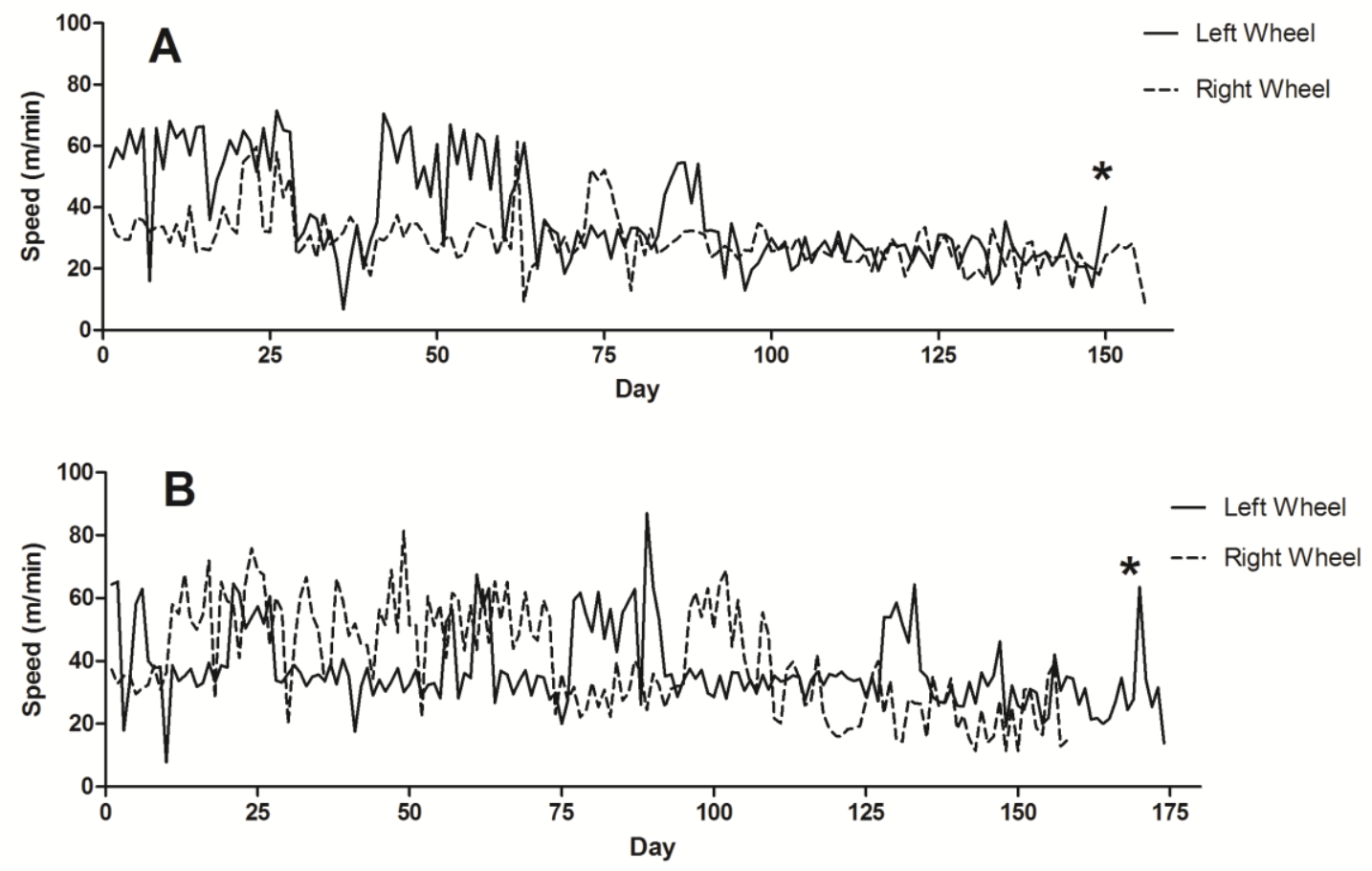

Figure 8 a,b - Average daily speed per wheel by mice S1/S2 (a) and S3/S4 (b). Data contains all available points while animals were housed in $2 \mathrm{v} 2$ cages. There was a significant preference $(p<0.0081)$ for the left wheel over the right wheel in both cages. 
Fig. 9 a,b - Mice S1/S2 and S3/S4

Linear Fit of Distance

Difference by Day of Measure
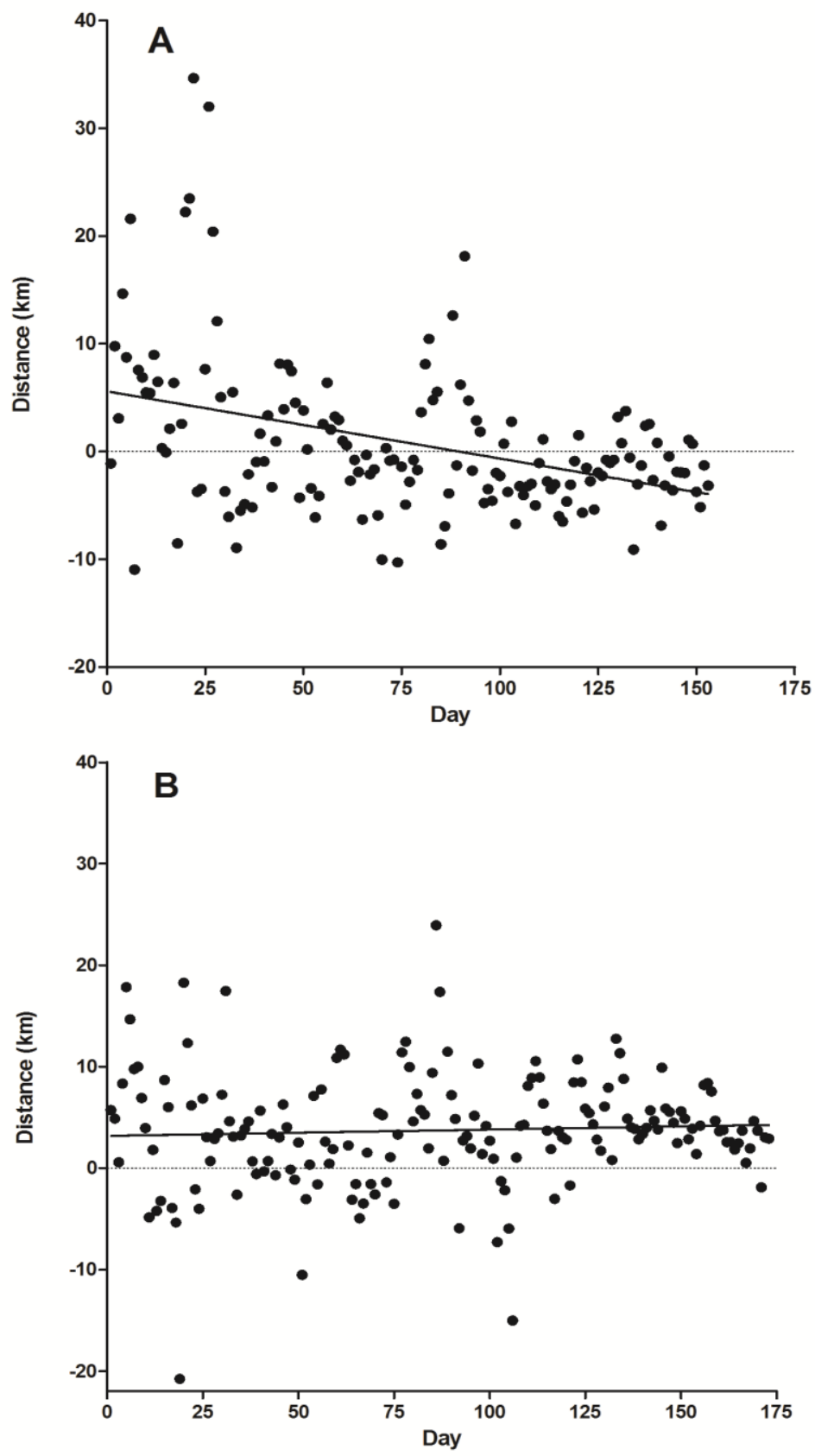

Figure $9 \mathrm{a}, \mathrm{b}$ - Linear fit of distance difference between wheels by day of measure for mice S1/S2 (a) and S3/S4 (b). Equations used: (a) $y=$ $5.588-0.0624(x) ;(b) y=3.183+0.0063(x)$. Where $y=$ the difference between wheels and $x=$ day of measure. (a) a significant fit was seen between wheels $(p<0.0001, r 2=0.15)$; (b) no significant fit was seen between wheels $(p=0.4664, r 2=0.0031)$. 
Fig. 10 a,b - Mice S1/S2 and S3/S4

Linear Fit of Duration

Difference by Day of Measure
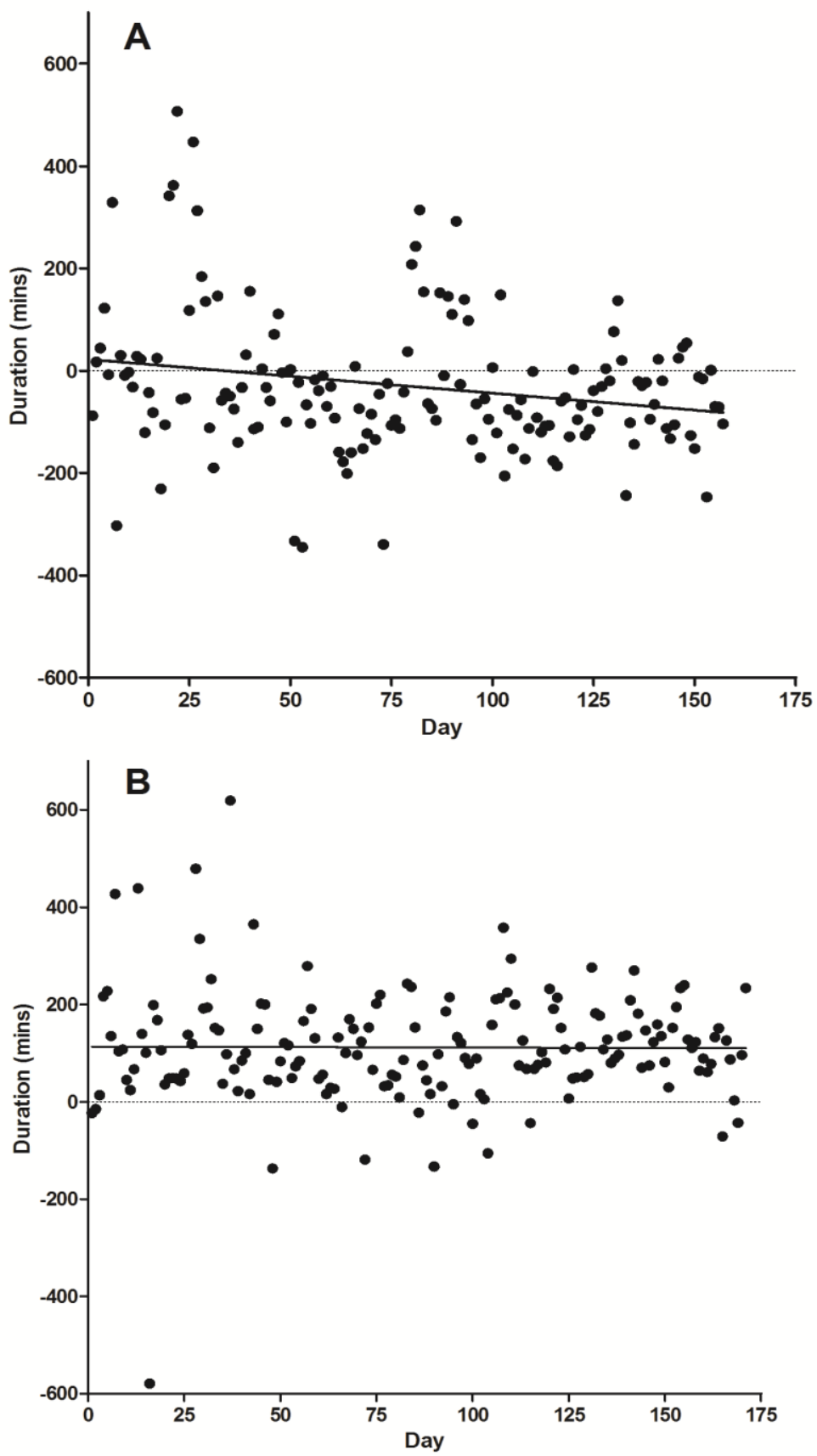

Figure $10 a, b$ - Linear fit of duration difference between wheels by day of measure for mice S1/S2 (a) and S3/S4 (b). Equations used: (a) $y=$ 22.13-0.6610(x); (b) $y=113.5-0.0165(x)$. Where $y=$ the difference between wheels and $x=$ day of measure. (a) a significant fit was seen between wheels $(p=0.0062, r 2=0.05)$; (b) no significant fit was seen between wheels $(p=0.9287, r 2=0.000047)$. 
Fig. 11 a,b - Mice S1/S2 and S3/S4

Linear Fit of Speed

Difference by Day of Measure
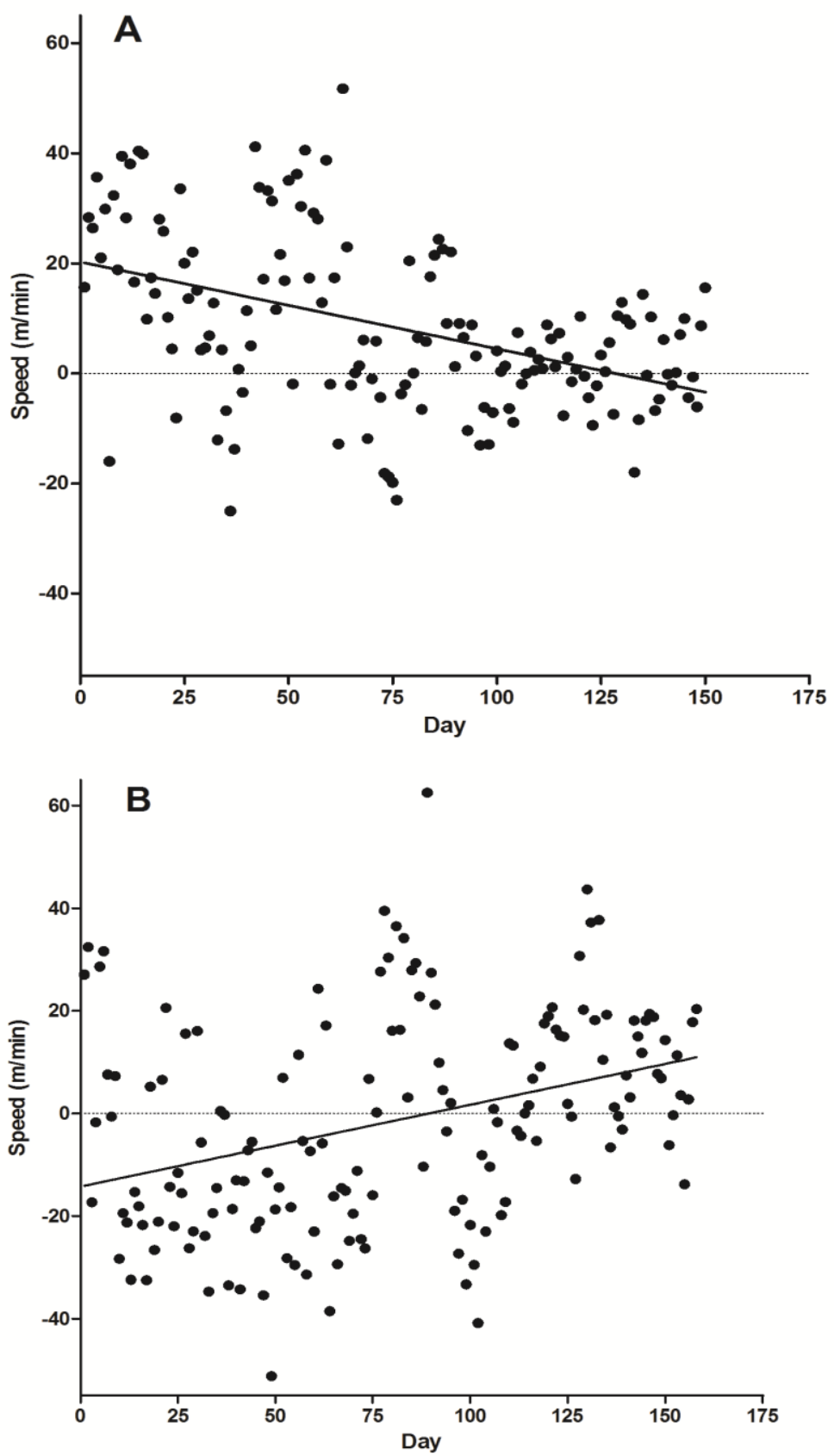

Figure $11 \mathrm{a}, \mathrm{b}$ - Linear fit of speed difference between wheels by day of measure for mice S1/S2 (a) and S3/S4 (b). Equations used: (a) $y=$ $20.26-0.1579(x) ;(b) y=-14.26+0.1595(x)$. Where $y=$ the difference between wheels and $x=$ day of measure. (a) a significant fit was seen between wheels $(p<0.0001, r 2=0.1967)$; (b) a significant fit was seen between wheels $(p<0.0001, r 2=0.1235)$. 
Fig. 12 - Average Daily Distance per Wheel During a Two Week Period

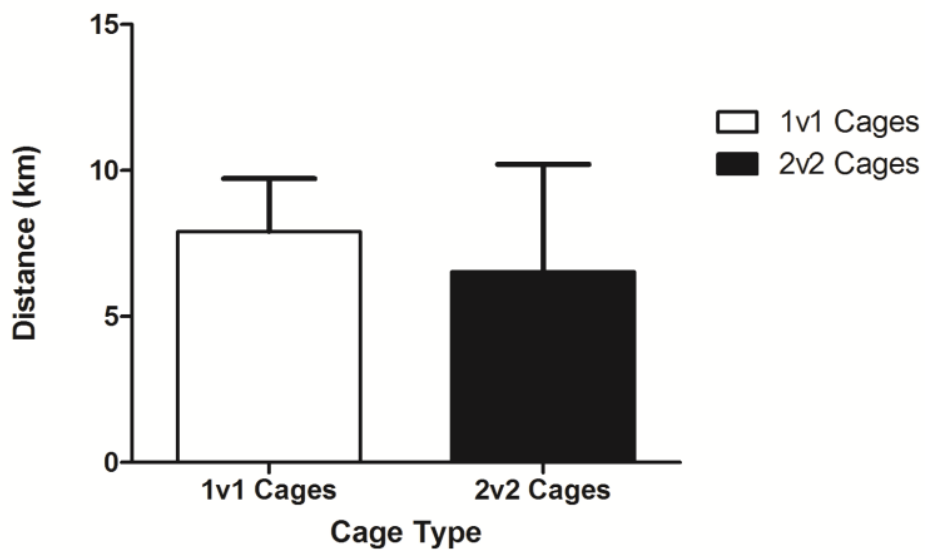

Figure 12 - Average daily distance per wheel for all 1v1 and $2 \mathrm{v} 2$ cages for a randomly chosen two week period. There was no significant difference $(p=0.067)$ between groups. 